REVIEW

\title{
Nutritional Status of Under Five Children in Ethiopia: A Systematic Review and Meta-Analysis
}

\author{
Ahmed Abdulahi ${ }^{1}$, Sakineh Shab-Bidar ${ }^{2}$, Shahabeddin Rezaei ${ }^{2}$, Kurosh \\ Djafarian $^{3^{*}}$
}

\footnotetext{
OPEN ACCESS

Citation: Ahmed Abdulahi, Shahabeddin Rezaei, Kourosh Djafarian, Sakineh Shabbidar. Nutritional Status of Under Five Children in Ethiopia: A Systematic Review and Meta-Analysis. Ethiop J Health Sci 2017;27(1):175. doi: http://dx.doi.org/10.4314/ejhs.v27i2.10 Received: November 22, 2016 Accepted: November 24, 2016 Published: March 1, 2017

Copyright: (C) 2015 Ahmed A, et al. This is an open access article distributed under the terms of the Creative Commons Attribution License, which permits unrestricted use, distribution, and reproduction in any medium, provided the original author and source are credited. Funding: Nil

Competing Interests: The authors declare that this manuscript was approved by all authors in its form and that no competing interest exists.

Affiliation and Correspondence:

${ }^{1}$ Department of Community Nutrition, School of Nutritional Sciences and Dietetics, Tehran University of Medical Sciences, International Campus (TUMS-IC), Tehran, Iran ${ }^{2}$ Department of Community Nutrition, School of Nutritional Sciences and Dietetics, Tehran University of Medical Sciences, Tehran, Iran

${ }^{3}$ Department of Clinical Nutrition, School of Nutritional Sciences and Dietetics, Tehran University of Medical Sciences, Tehran, Iran *Email: kdjafarian@tums.ac.ir
}

\begin{abstract}
BACKGROUND: Undernutrition is the outcome of insufficient food intake and recurrent infectious diseases. The baseline levels of undernutrition remain so high that Ethiopia still needs to continue substantial investment in nutrition.Therefore, the aim of this study was to obtain estimates of over-time trends in the prevalence of undernutrition in Ethiopia and to determine risk factors for undernutrition among children of under five years of age.

METHODS: Cross-sectional studies published in English from 1997 to 2015 focusing the prevalence of stunting, wasting and underweight in children aged 0-5 years $(n=39,585)$ in Ethiopia were included in this systematic review and meta-analysis. We searched in PubMed and Scopus databases and other articles manually. Two review authors independently selected studies for inclusion, extracted data and assessed the risk of bias in the included studies. The protocol number of the study is PROSPERO 2015: CRD42015027940.

RESULTS: Eighteen studies were included and the overall pooled prevalence estimate of stunting, underweight and wasting was 42.0\% (95\% CI: 37.0, 46.0), 33.0\% (95\% CI: 27.0, 39.0) and 15.0\% (95\% CI: 12.0, 19.0), respectively. The sensitivity analyses resulted in the prevalence of stunting, $40 \%$ (95\% CI: 32.0, 48.0; I2=99.19\%), prevalence of underweight, 33\%(95\% CI: 24.0, 42.0; $\left.I^{2}=99.34 \%\right)$ and wasting rate equal to $19 \%(95 \%$ CI: 14.0, 24.0; $I 2=99.19 \%)$. Cumulative analysis revealed a stabilization trend of stunting and underweight (1996-2010) followed by an upward trend (2010-2014). Child age, child sex, complementary food, poor dietary diversity, diarrheal diseases, maternal education, maternal height, residential area and socio- economic status were significant risk factors for undernutrition.

CONCLUSION: The result of the meta-analysis of thes observational studies revealed that the trend of undernutrition in Ethiopia indicates that there is an increment of chronic malnutrition cases in recent years, and the prevalence of undernutrition remains extremely high. Thus, the implementation of policies to reverse child undernutrition should get maximum emphasis.
\end{abstract}

KEYWORDS: Undernutrition, children, prevalence and Ethiopia 


\section{INTRODUCTION}

One of the world's most important difficulties is to secure, sufficient and substantial nourishment for all in an ecologically manageable way. This audit investigates the inter- relationships of sustenance, well-being, and the environment and their part intending to continuous micro-nutrient insufficiency, otherwise called "shrouded craving", influencing in excess of two billion individuals around the world (1). While the intricacy and vital risk factors of undernutrition have been well comprehended for quite a long time, the scaling of nourishment and sustenance framework approaches that join maintainable farming went for enhanced eating regimen assorted qualities and livelihoods have been restricted in their advancement and usage (2). On the other hand, an incorporated framework methodology to lessen shrouded yearning could conceivably serve as a maintainable open door.

According to the United Nations Children Fund (UNICEF), undernutrition is the outcome of insufficient food intake and recurrent infectious diseases (3). Undernutrition is a group of disorders that includes stunting, wasting and underweight. There is a strong evidence that undernutrition is associated with faltered growth, delayed mental development, and reduced intellectual capacity. They can also no longer sustain natural bodily capacities, such as resisting infections and improving from disease (4).

Child undernutrition continues to be a key public health problem in developing countries including Ethiopia. Ethiopia has demonstrated promising progress in reducing levels of undernutrition over the past decade. However, the baseline levels of undernutrition remain so high that the country still needs to continue substantial investment in nutrition (5). According to Ethiopian Demographic and Health Survey, there is a substantial variation of undernutrition in Ethiopia. For instance, there is regional variation in the prevalence of stunting in children; the estimated prevalence of chronic malnutrition is above the national average in Affar (49\%), Tigray (44\%), South Nation and National People (44\%) and Amhara (42\%) compared with a national average of $40 \%(6)$.

The purpose of this systematic review and metaanalysis was to obtain estimates of over-time trends in the prevalence of undernutrition (stunting, wasting and underweight) in Ethiopia and to determine risk factors for undernutrition among children of under five years of age by systematically reviewing original research on this topic.

\section{MATERIALS AND METHODS}

Search strategy: Two investigators (AAA and SR) independently searched electronic databases in Scopes and PubMed for studies published from 1997 to 2015 using the key terms "malnutrition", "undernutrition", "over nutrition", "nutritional status", "protein-energy malnutrition", "child nutrition disorders" and "infant nutrition disorders" combined with the term "Ethiopia" in duplicate. A manual search for additional relevant studies using references from retrieved articles was also performed. Conference abstracts and unpublished studies were excluded. We restricted the searches to human studies with English language restriction placed on the searches. The meta-analysis is reported in accordance with the PRISMA guideline (7). Literature was downloaded to Endnote (version X7, for Windows, Thomson Reuters, Philadelphia, PA, USA) to maintain and manage citation and facilitate review process.

Types of studies, participants, and comparators: We included all community based cross-sectional studies involving households with children aged under five years in Ethiopia. Studies that focused specifically on mother-child pairs and child only were included. Moreover, studies that analyzed data from their original survey and ones that analyzed secondary data were also included. We excluded studies on children aged greater than five years, adolescents and adults, studies used samples recruited from hospitals (i.e. with a possible or diagnosed pathological condition), and studies which used non-healthy participants. The comparators had to be studies that only reported prevalence, and for studies that assessed risk factors, comparators had to be any of normal, undernourished or over nourished households (or pairs). When one population was reported in more than one publication, only the most recent one or the one providing maximum information was included to avoid sample overlapping.

DOI: http://dx.doi.org/10.4314/ejhs.v27i2.10 
Outcome measures: The primary outcome was the prevalence of undernutrition (stunting, underweight and wasting). Children Height forAge, Weight-for Age and Weight-for-Height below -2SD were characterized as stunted, underweight and wasted, respectively, using WHO 2006 standards, the U.S National Center for Health Statistics (NCHS), Centers for Disease Control and Prevention and World Health Organization (WHO) reference population. When the prevalence was not reported, we contacted the authors, and if they did not respond or told us that the required data were not available, we excluded the study(ies) from the analysis. Other secondary outcomes considered in this systematic review and meta-analysis were the risk factors significantly related to high prevalence of undernutrition.

Data abstraction: Titles and/or abstracts were retrieved using search strategy and those from additional sources were screened by two independent authors (AAA and SR) to identify studies that would be potentially included. The full text of these potentially eligible studies were retrieved and assessed for eligibility by two review team members. Any discrepancies were resolved jointly. We extracted information on study author, year of publication, journal, design, area/place (rural/urban), sample size, response rate, prevalence of undernutrition and 95\% CI, time of data collection, type of participants (sex and age) and risk factors significantly related to high prevalence of under-nutrition. For the analysis of the risk factors, we considered and collected risk factors which were mentioned in two or more studies. E-mails were sent to the corresponding or first authors of the studies or abstracts for missing information and waiting time of 3-4 weeks were taken for the responses. If there were no responses, we excluded the study or the parameter that was not available.

Assessment of risk of bias in included studies: Two review authors (AAA and SR) independently assessed the qualities of the eligible studies and controlled for possible bias by adapting specific protocol/sample characteristics and the criteria proposed in the Newcastle-Ottawa Scale for nonrandomized studies (8,9). The following parameters were assessed: sampling strategy, inclusion/exclusion criteria, sample size, index. cut-offs and reference for assessment of child nutritional status, criteria to identify undernutrition and covariates included in statistical models to assess determinants/risk factors. The final scoring system comprised 11 criteria of rating different quality elements for each eligible paper (Supp. Table 1). Authors recommended scale weights for each element of the scoring system, as proposed in other meta-analyses. Studies were classified into three quality groups and labeled $\mathrm{A}$ if they managed to obtain 9-12 points, $\mathrm{B}$ when 5-8 points were collected and $\mathrm{C}$ when they scored less than 5 points. Studies of high quality, with less estimated risk of bias, were allocated to class ' $A$ ' and were subsequently used in the sensitivity analyses.

Assessment of heterogeneity and data synthesis: After detailed examination of the study by the investigators, the existence of homogeneity in the prevalence reported in the studies was tested with $\mathrm{I}^{2}$ and Cochrane's Q $(10,11)$. The Cochrane's Q statistic approximate to the $\chi^{2}$ test of heterogeneity was tested in an a-level of 0.10 (10). $\mathrm{I}^{2}$ describes the total variation across studies and was used to identify violation in the assumption of homogeneity when $\mathrm{I}^{2}>60 \%$ (11).

Statistical methods: Statistical analysis was carried out using the statistical software package Stata version 13 (Stata corporation, college station, Texas, USA). The effect size of the metaanalysis was the prevalence of stunting, wasting or underweight, computed-when not referred to-as the ratio of the events (number of stunting, wasting or underweight participants)/total (total number of participants). The pooled prevalence of stunting, wasting or underweight was estimated by random effects. We examined risk factors for undernutrition that met the meta-analysis eligibility criteria, by looking at the adjusted ORs and $95 \%$ CIs reported in each study. A random effects model was utilized to pool the effect sizes of the individual risk factors taking into account both the sampling error and between study heterogeneity by the generic inverse variance method by the user written "metan" command in Stata (version 13) software (12). Effect size was pooled from all eligible studies using the DerSimonian-Laird Random effects model (REM)

DOI: http://dx.doi.org/10.4314/ejhs.v27i2.10 
for meta-analysis (13). This model was preferred to a fixed effect model, since it is based on the assumption that a distribution of effects exists, resulting in heterogeneity among study results (14). Additionally, the heterogeneity was separately estimated using a $\chi^{2}$ test, Q statistics with corresponding I 2 statistics. In analyses where $\mathrm{I}^{2}>60 \%$ was observed, we explored possible sources of heterogeneity by sub-group analyses based on the definition used for the nutritional status of children. For space economy, results are presented in tables and forest plots where prevalence rates, $\mathrm{OR}$ and $95 \%$ confidence intervals (CI) are figured out for every study inserted in the model and for the overall estimate.

To retrieve the extent of publication bias, funnel plots were scattered and tested for asymmetry and, additionally, Egger's test was computed with the user written "metabias" command in Stata (version 13) software (12). Subgroups analysis was conducted for the studies according to the region/place of the study takes placed. The effect of aberrant studies was examined via sensitivity analyses after the exclusion of studies with low and poor quality, as classified by the quality scoring system (B and C class studies). Over-time trends in the prevalence of undernutrition (stunting, wasting and underweight) was estimated via cumulative analyses which calculated the cumulative evidence at the time of the appearance of each data set. To avoid systematic bias, studies were entered into the model of each cumulative meta-analysis successively according to the data collection time and not to the publication time. However, for those studies in which dates of data collection were not reported, we used the dates of publication for the purpose of the cumulative analysis.

\section{RESULTS}

Literature searches and selection: In the initial search, we found 1,889 records in electronic search databases of PubMed $(1,342)$ and Scopus (547). From these 1,558 records remained after removing duplication. After examination and screening for the title and abstract, 1,532 records were excluded. We assessed the full texts of 26 remaining records for eligibility, and 8 records were further excluded for not fulfilling the inclusion criteria. Finally, only 18 of the retrieved studies were used in the meta-analyses (15-32) (Figure 1).

Characteristics of the studies: The meta-analysis included 18 different studies covering a total of 39,585 children aged 0-5 years. Sample size ranged from 100 to 10,449 participants. The majority (14/18) of the studies were conducted in rural and urban areas. Thirteen studies reported sex of participants. Accordingly, boys contributed to $51.3 \%$ (19437) (Table 1).

Systematic review: The prevalence of stunting, underweight and wasting ranged from $14.6 \%$ to $67.8 \%, 12.0 \%$ to $47.2 \%$ and $4.5 \%$ to $42.0 \%$ respectively in individual studies (Table 1). Studies were included representing data from four regions of Ethiopia (18 studies), country level, South Ethiopia, North Ethiopia and East Ethiopia with inclusive of all the three prevalence studies. The highest number of studies was reported from country level studies, North and South Ethiopia covering five studies each, and the least was from East Ethiopia covering only three studies. The highest prevalence of stunting was reported in East Ethiopia $67.8 \%$, and the least was in North Ethiopia $14.6 \%$. The highest prevalence of underweight was reported in country level studies (DHS) $(47.2 \%)$, and the least was in South Ethiopian studies (12\%). Similarly, the highest prevalence of wasting was reported in country level studies (DHS) 42\%, and the least was reported in North Ethiopian studies $(4.5 \%)$ (Table $1)$.

Meta-analysis: Eighteen studies were included for the analysis to determine the prevalence of stunting; the overall pooled prevalence estimate was $42.0 \%$ (95\% CI: 37.0, 46.0). Seventeen studies were included for the analysis to determine the prevalence of underweight; the overall pooled prevalence estimate was $33.0 \%$ (95\% CI: 27.0, 39.0). Sixteen studies were included for the analysis to determine the prevalence of wasting; the overall pooled prevalence estimate was $15.0 \%$ (95\% CI: 12.0, 19.0).

DOI: http://dx.doi.org/10.4314/ejhs.v27i2.10 


\section{Flow of Information}

\section{Identification}

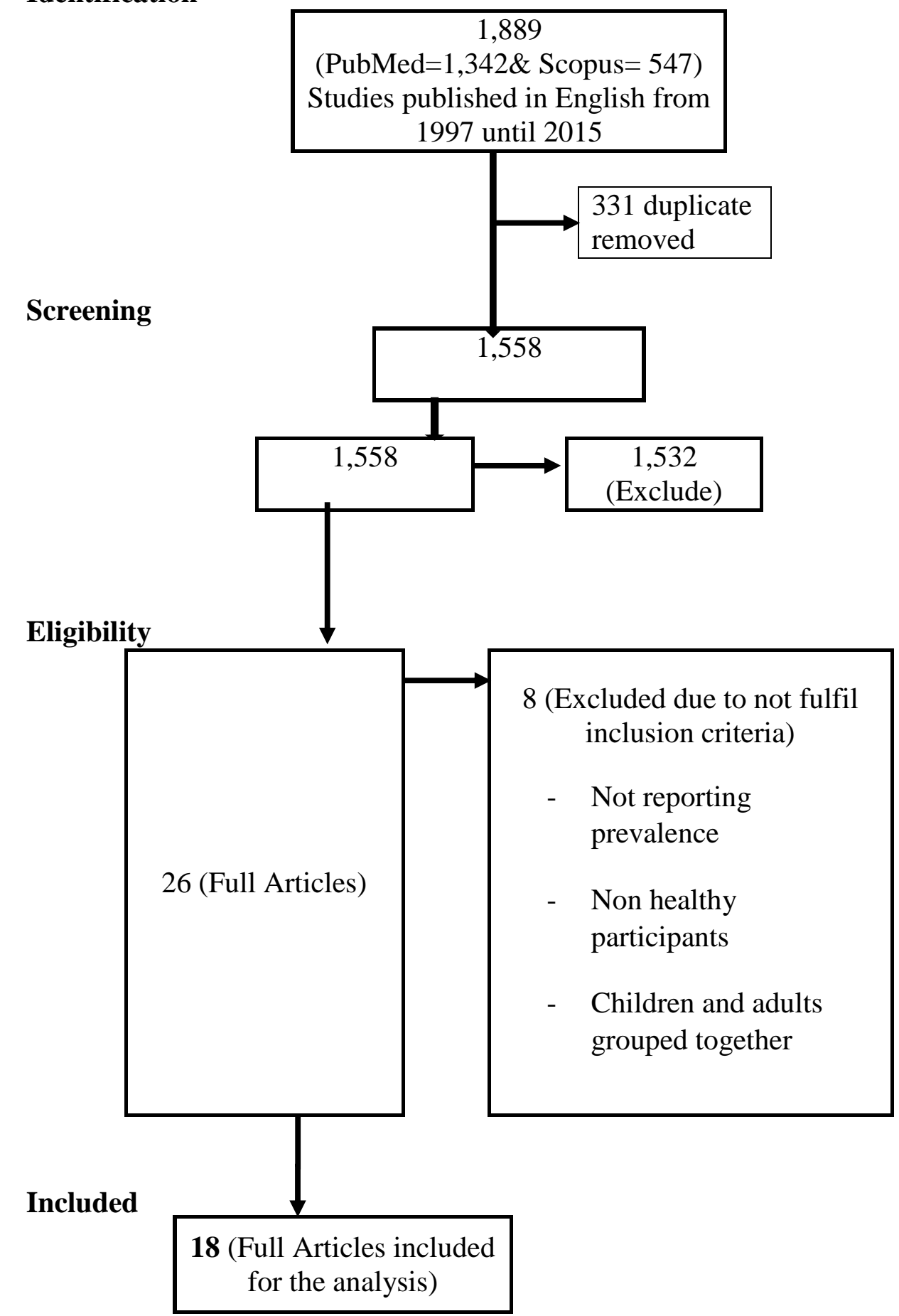

Figure 1: Flow chart of the selection process for the studies included in the analyse 
Table 1: Summary of Included Studies Evaluating the Prevalence Rate and Risk Factors of Undernutrition in Ethiopia

\begin{tabular}{|c|c|c|c|c|c|c|c|c|c|c|c|c|}
\hline Author & $\begin{array}{l}\text { Publication } \\
\text { Year }\end{array}$ & $\begin{array}{l}\text { Study } \\
\text { design }\end{array}$ & $\begin{array}{c}\text { Rural } \\
\text { /Urban }\end{array}$ & $\begin{array}{l}\text { Data } \\
\text { collection }\end{array}$ & $\begin{array}{l}\text { Age } \\
\text { range }\end{array}$ & $\begin{array}{l}\text { Sample } \\
\text { size }\end{array}$ & $\begin{array}{l}\text { response } \\
\text { rate }\end{array}$ & $\begin{array}{l}\text { Female } \\
\%\end{array}$ & $\begin{array}{c}\text { Stutnting } \\
\text { (Prev.) }\end{array}$ & $\begin{array}{c}\text { Wasting } \\
\text { (Prev.) }\end{array}$ & $\begin{array}{c}\text { Underweight } \\
\text { (Prev.) }\end{array}$ & $\begin{array}{l}\text { Quality } \\
\text { Score }\end{array}$ \\
\hline P. H Nguyen & 2014 & CS & $R \& U$ & NR & $0-5 y$ & 3000 & NR & NR & 44.4 & 6.7 & 23.8 & 5 \\
\hline E. GURMU & 2013 & CS & $R \& U$ & 2004 & $0-5 y$ & 8827 & NR & 48.8 & 43.6 & NR & NR & 4 \\
\hline DHS & 2007 & CS & $\mathrm{R} \& \mathrm{U}$ & 2005 & $0-5 \mathrm{y}$ & 4586 & NR & 49.5 & 46.5 & 10.5 & 38.4 & 9 \\
\hline T. Harpham & 2005 & CS & $\mathrm{R} \& \mathrm{U}$ & 2002 & $6-18 \mathrm{~m}$ & 1722 & NR & NR & 38 & 42 & NR & 9 \\
\hline DHS & 2002 & CS & $\mathrm{R} \& \mathrm{U}$ & 2000 & $0-5 y$ & 10449 & NR & 49.7 & 51.5 & 10.5 & 47.2 & 9 \\
\hline M. Asfaw & 2015 & CS & $R \& U$ & 2013 & $6-59 \mathrm{~m}$ & 778 & 97.7 & 50.6 & 47.6 & 13.4 & 29.2 & 12 \\
\hline A.Bogale & 2013 & CS & $\mathrm{R} \& \mathrm{U}$ & 2007 & $0-5 y$ & 100 & NR & NR & 29 & NR & 12 & 8 \\
\hline Amare Deribew & 2010 & CS & $\mathrm{R} \& \mathrm{U}$ & NR & $0-5 y$ & 2408 & NR & 49.3 & 40.4 & 5.1 & 34.2 & 6 \\
\hline M. Umeta & 2003 & CS & $\mathrm{R}$ & 1996 & $6-11 \mathrm{~m}$ & 305 & 100 & 52 & 36.1 & 13.1 & 41.3 & 8 \\
\hline B. LINDTJØRN & 1997 & CS & $\mathrm{R}$ & NR & $0-5 \mathrm{y}$ & 268 & NR & 83 & 42.1 & 8.6 & 36 & 6 \\
\hline A.Motbainor & 2015 & CS & $\mathrm{R} \& \mathrm{U}$ & 2013 & $0-60 \mathrm{~m}$ & 3964 & 96.45 & 44 & 37.6 & 17.3 & 21.9 & 11 \\
\hline M. Alemayehu & 2015 & CS & $\mathrm{R}$ & 2013 & $0-5 y$ & 605 & 95.4 & 50.6 & 56.6 & 34.6 & 45.3 & 12 \\
\hline G. Asres & 2011 & CS & $\mathrm{U}$ & 2010 & $1-5 \mathrm{y}$ & 794 & NR & 51.5 & 14.6 & 4.5 & 37.2 & 9 \\
\hline A. MULUGETA & 2010 & CS & $\mathrm{R} \& \mathrm{U}$ & 2005 & $0-5 y$ & 318 & NR & 50.3 & 46.9 & 11.6 & 33 & 7 \\
\hline J. Haidar & 2005 & CS & $\mathrm{R}$ & 2003 & $6-59 \mathrm{~m}$ & 200 & NR & NR & 44.5 & 9 & 25 & 9 \\
\hline Y. Fekadu & 2015 & CS & $\mathrm{U}$ & 2013 & $6-23 \mathrm{~m}$ & 214 & 98 & 48.1 & 22.9 & 17.5 & 19.5 & 12 \\
\hline R. Fentaw & 2013 & CS & $\mathrm{R}$ & NR & $0-5 y$ & 180 & NR & NR & 67.8 & 12.8 & 46.1 & 7 \\
\hline P. Salama & 2001 & $\mathrm{CS}$ & $\mathrm{R} \& \mathrm{U}$ & 1999 & $6-59 \mathrm{~m}$ & 867 & NR & NR & NR & 29.1 & NR & 10 \\
\hline
\end{tabular}

CS: cross-sectional, NR: not reported R: rural, U: urban, y: years, m: months

The heterogeneity of the prevalence estimates among the subgroups of 18 studies on stunting was very high $\left(\mathrm{I}^{2}=98.5 \%\right.$ and $\left.\mathrm{p}=0.433\right)$. The heterogeneity of the prevalence estimates among the subgroups of 17 studies on underweight was also very high $\left(\mathrm{I}^{2}=99.0 \%\right.$ and $\left.\mathrm{p}=0.693\right)$. The heterogeneity of the prevalence estimates among the subgroups of 16 studies on wasting was very high $\left(\mathrm{I}^{2}=98.9 \%\right.$ and $\left.\mathrm{p}=0.205\right)$ (data not presented).

In subgroup analysis, the pooled prevalence estimate of stunting was high at country level studies, $45.0 \%$ (95\% CI: 41.0, 49.0; $\left.\mathrm{I}^{2}=97.92 \%\right)$, and the least was in South and North Ethiopian studies, $40.0 \%$ (95\% CI: 35.0, 45.0; $\mathrm{I} 2=83.37 \%$ ) and $40.0 \%$ (95\% CI: 26.0, 54.0; $\mathrm{I}^{2}=99.04 \%$ ), respectively (Figure 2). 
In subgroup analysis, the pooled prevalence estimate of underweight was high at country level studies, $36.0 \%$ (95\% CI:23.0, 50.0; I2=99.7\%), and the least was at East Ethiopia studies, $29.0 \%$ (95\% CI: 25.0, 33.0; $\mathrm{I}^{2}=99.44 \%$ ) (Supplementary Figure 1). In subgroup analysis, the pooled prevalence estimate of wasting was high in East Ethiopian studies, $20.0 \%$ (95\% CI: 9.0, 30.0; $\mathrm{I} 2=94.6 \%$ ), and the least was at South Ethiopia studies, $10.0 \%$ (95\% CI: 5.0, 15.0; I2=94.56\%) (Supplementary Fig. 2).

\section{Prevalence of Stunting}

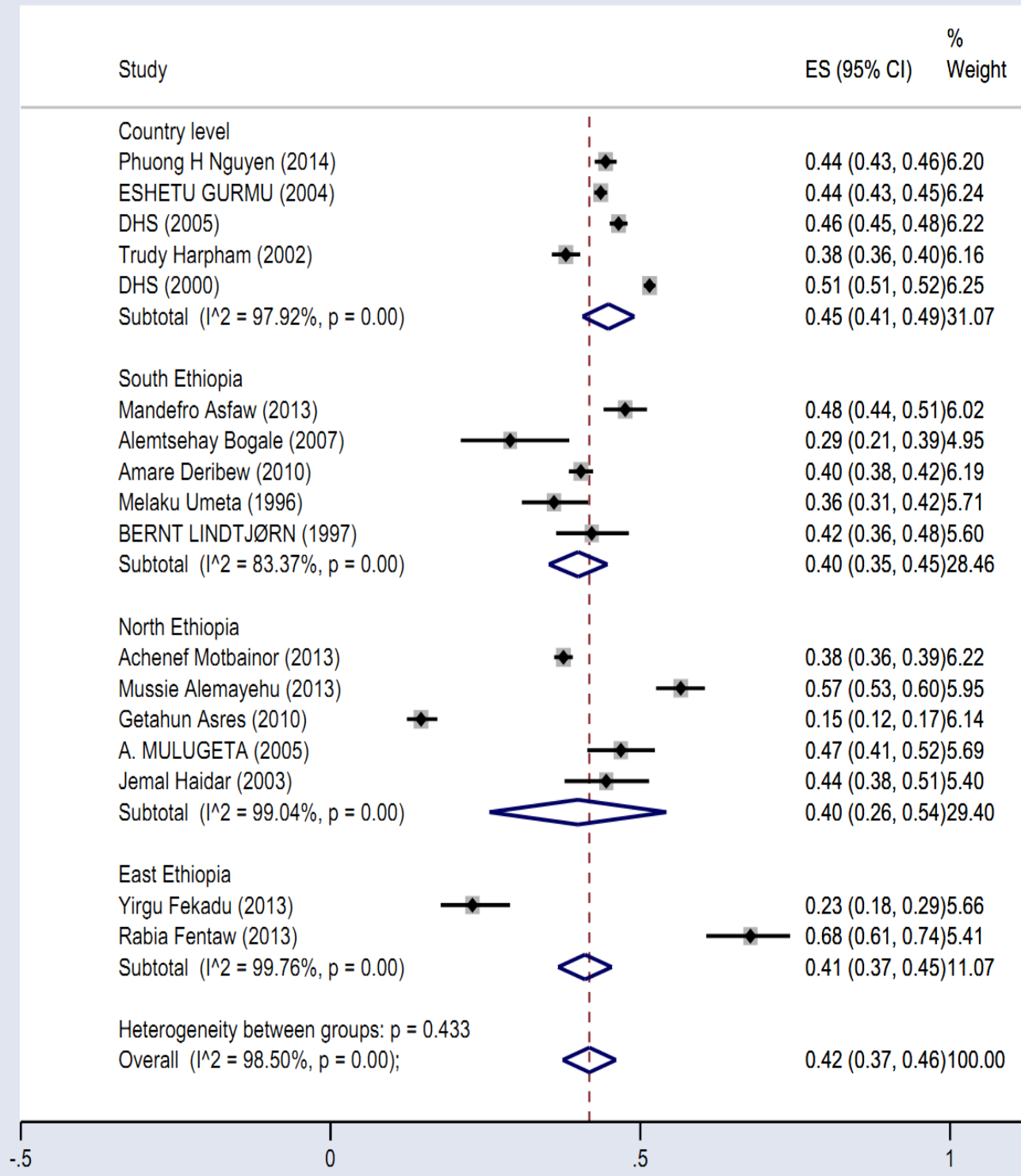

Figure 2: The Prevalence Rate of Stunting in children and its 95\% CI

According to the year and the location of the studies assessed, he midpoint of each line illustrates the prevalence rate estimated in each study. The diamond design shows the prevalence rate throughout the country for all the studies.

DOI: http://dx.doi.org/10.4314/ejhs.v27i2.10 
Sensitivity analysis: Sensitivity analyses were performed for all of the studied effect sizes (stunting, underweight and wasting prevalence rates) by removing data from the meta-analytic model in order to examine influence of low quality and high-bias-risk studies on the overall estimate. According to the quality score (Table 2), only studies of higher quality $(\mathrm{n}=10,55.56 \%)$ were included in the sensitivity analyses. The sensitivity analyses resulted in the prevalence of stunting, $40 \%$ (95\% CI: $32.0,48.0 ; \mathrm{I}^{2}=99.19 \%$ ), prevalence of underweight, $33 \%$ (95\% CI: 24.0, 42.0; $\left.\mathrm{I}^{2}=99.34 \%\right)$ and wasting rate equal to 19 per 100 (95\% CI: 14.0, 24.0; $\mathrm{I}^{2}=99.19 \%$ ). The sensitivity analysis showed that quality scores did not significantly affect the overall pooled prevalence, and the heterogeneity remained significant.
Subgroup analyses based on the definition used for the nutritional status of children revealed that prevalences of stunting, underweight and wasting by using the U.S National Center for Health Statistics (NCHS), Centers for Disease Control and Prevention, and World Health Organization (WHO) reference population were $44 \%$ (95\% CI: 40.0, 48.0; I2=97.75\%), $37 \%$ (95\% CI: 27.0, 46.0; $\mathrm{I} 2=99.39 \%)$, and $19 \%(95 \% \mathrm{CI}: 14.0,25.0$; $\mathrm{I} 2=99.19 \%)$, respectively. Accordingly, the prevalence of stunting, underweight and wasting by using WHO child growth standards were $37 \%$ (95\% CI: 27.0, 47.0; I2=99.11\%), $29 \%$ (95\% CI: 24.0, 35.0; I2=95.60\%), and $11 \%$ (95\% CI: 7.0, $20.0 ; \mathrm{I} 2=92.43 \%$ ), respectively. Similarly, in subgroup analysis, the heterogeneity remained significant (data not presented).

Table 2: Collective results of the random pooled and sensitivity analyses

\begin{tabular}{cccccc}
\hline & $\mathbf{\%}$ & $\mathbf{9 5 \%} \mathbf{C I}$ & $\mathbf{n}$ & $\mathbf{Q}$ & $\mathbf{I}^{\mathbf{2}} \mathbf{( \% )}$ \\
\cline { 2 - 6 } $\begin{array}{c}\text { Random Pooled } \\
\text { Analysis }\end{array}$ & & & & & \\
Stunting & 42 & $37-46$ & 38718 & 1069.85 & 98.50 \\
Underweight & 33 & $27-39$ & 28169 & 1398.24 & 99.00 \\
$\quad$ Wasting & 15 & $12-19$ & 30658 & 1428.34 & 98.95 \\
\hline Sensitivity Analysis & & & & & \\
$\quad$ Stunting & 40 & $32-48$ & 23312 & 987.55 & 99.19 \\
Underweight & 33 & $24-42$ & 21590 & 1061.20 & 99.34 \\
Wasting & 19 & $14-24$ & 24179 & 1111.21 & 99.19 \\
\hline
\end{tabular}

Cumulative analysis: Cumulative meta-analyses forest plots confirmed stabilization trend forstunting for the period of 1996 to 2010 and upgrading trend for the period of 2010 to 2014 (Suppl. Figure 3). Similarly, stabilization trend for the period 1996 to 2010 and upgrading trend for the period 2010 to 2014 were exhibited when cumulative meta-analyses were run for underweight (Suppl. Figure 4). On the other hand, the cumulative meta-analyses forest plots confirmed stabilization trend for wasting for the period of 1996 to 2013 and upgrading trend for the period of 2013 to 2014 (Suppl. Figure 5).

DOI: http://dx.doi.org/10.4314/ejhs.v27i2.10 


\section{Risk Factors for Stunting}

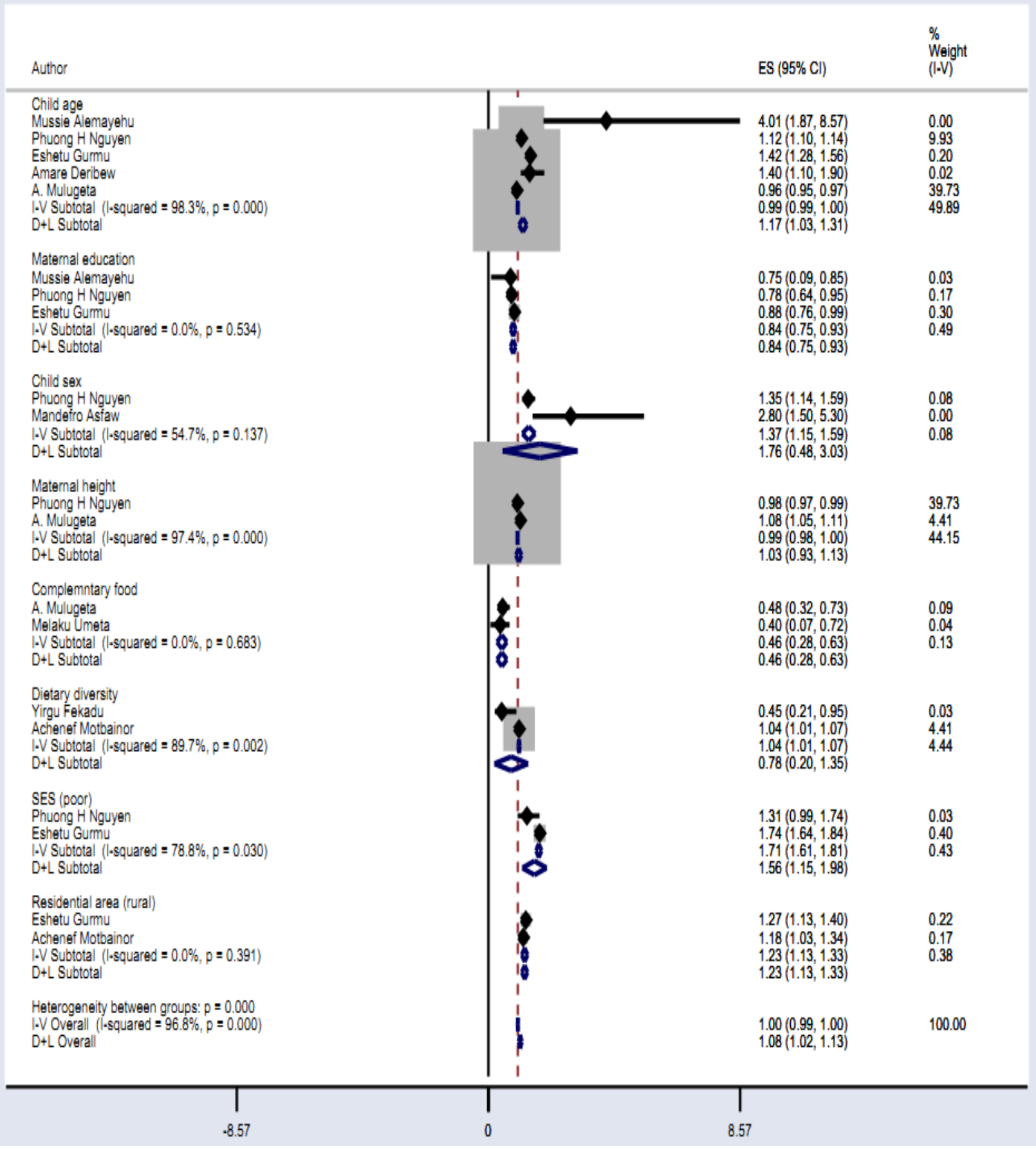

Figure 3: Odds Ratios and 95\% Confidence Intervals in cross-sectional Studies of Risk Factors for stunting.

According to the author and the risk factors of studies assessed, the midpoint of each line illustrates the estimated odds ratio in each study. The diamond design shows the OR throughout the studies.

DOI: http://dx.doi.org/10.4314/ejhs.v27i2.10 
Risk factor analysis: Nine studies were included for the analysis of risk factors for stunting. Accordingly, eight risk factors had data that could be used in the quantitative meta-analysis. The pooled odds ratios ranged from 0.46 to 1.76 [complementary food to child sex]. Greater heterogeneity was observed among studies evaluating child age, child sex, complementary food (cereal-based), poor dietary diversity, maternal education (primary school), maternal height (BMI), residential area (rural) and socioeconomic status (poor) as risk factors for stunting (Figure 3). Similarly, seven studies were included for the analysis of risk factor for underweight, and five risk factors were used in the quantitative meta-analysis. The pooled odds ratios ranged from 0.47 to 3.78 [complementary food to diarrheal disease]. Greater heterogeneity was also observed among studies evaluating child age, child sex, diarrheal diseases, complementary food and maternal height as risk factors for underweight (Suppl. Figure 6). Five studies were included for the analysis of risk factors for wasting. Accordingly, three risk factors: child age, child sex and diarrheal disease were identified, and the pooled odds ratios ranged from 1.20 to 2.28 [child sex to diarrheal disease] (Suppl. Figure 7).

Publication bias:We assessed the funnel plot for a symmetry by visual inspection for stunting, underweight and wasting, it appeared quite symmetrical and found no publication bias and Egger's test also revealed evidence of no publication bias [Egger's test $\mathrm{p}=0.32$ (Figure 4), $\mathrm{p}=0.44$ (Sup. Fig 8) and $\mathrm{p}=0.09$ (Suppl. Fig 9), respectively].

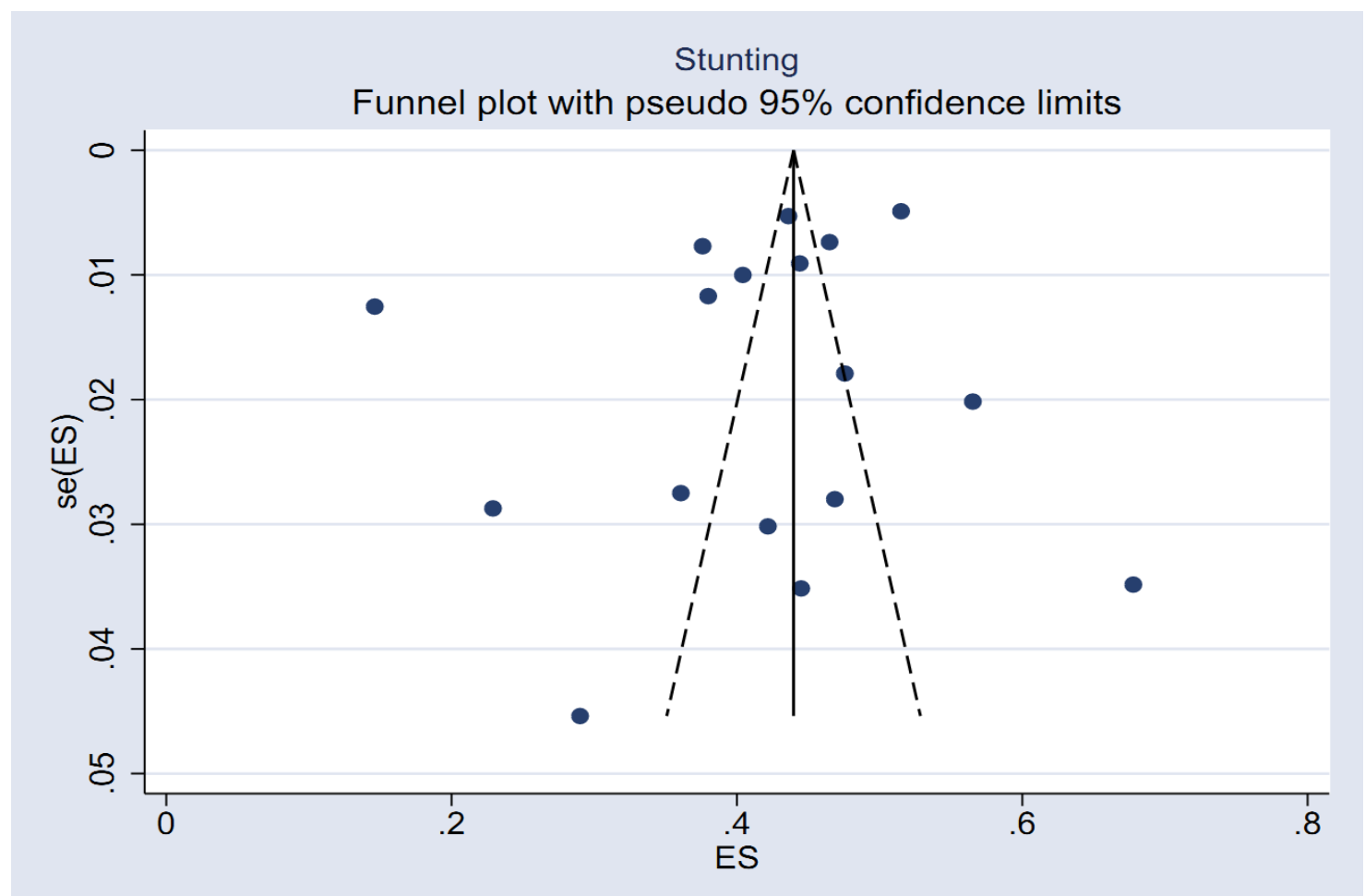

Figure 4: Funnel Plot to Assess Publication Bias for Stunting

\section{DISCUSSION}

Data containing 39,585 children under five years of age were included in the present study. A total of 18 studies were entered into the meta-analysis.
The global trend in prevalence of stunting and numbers of children affected is decreasing. Between 1990 and 2014, stunting prevalence declined from $39.6 \%$ to $23.8 \%$. In 2014 , the

DOI: http://dx.doi.org/10.4314/ejhs.v27i2.10 
global wasting rate was 7.5 per 100 , which means that approximately 1 out of every 13 children in the world was wasted in 2014(33).

During the study period, 1997-2014, the prevalence of child undernutrition increased slightly and appeared to have reached a plateau during the year 2013. However, there was no data collected and analyzed for the years 2001, 2006, 2008, 2009, 2011 and 2012. Therefore, it is difficult to approximate the latest trend of child undernutrition in Ethiopia. However, the analysis of individual studies shows a slight increment in chronic malnutrition din the years 2010 to 2014, but a slight decline in the percentage of undernutrition and wasting in Ethiopia in the years 2010 to 2014. The possible reason for upward trend in chronic malnutrition between 2010 and 2014 is due to La Niña-caused drought in Ethiopia. La Niña represents the increase in the surface temperature in the central and eastern equatorial Pacific Ocean, and it is believed to be the cause of extreme events like drought and flood $(34,35)$. Therefore, due to this climate change, there was a decline of short and long rains, causing collapse in both agricultural production and associated labor market; this event can predict chronic malnutrition (36). According to the fourth Ethiopian Health Sector Development Plan 2010/11 to 2014/15 (HSDP IV) (37), which aimed to reduce undernutrition among under five population by $30 \%$ by 2015 , was far from being achieved. Therefore, this implies that as per the global trend of child undernutrition, Ethiopia has seen very slow progress.

In our review, random effect models were used for meta-analysis, considering the likelihood of significant heterogeneity amongst studies which were tested with the Q test. The pooled prevalence of subgroup analysis showed marked differences on the prevalence of undernutrition among regions; country level studies reported high prevalence of stunting and underweight, and high prevalence of wasting was shown in East Ethiopian studies. In contrast, the prevalence of wasting is considerably lower in South Ethiopian studies. This difference is due to the fact that Eastern part of Ethiopia faced recurrent drought, resulting in insufficient food production at the household level, and the global increases in food prices haveresulted in food insecurity that may have contributed to the increasing trend of wasted children in the area (38).

Meta-analysis results highlighted common risk factors for child undernutrition. Despite significant heterogeneity in ORs, many studies had $\mathrm{OR}>1$, indicating an increased risk for undernutrition. The combined results of the ten cross sectional studies about the risk factors for child undernutrition indicated that nine factors: child age, child sex, complementary food (cerealbased), diarrheal disease, dietary diversity, maternal education (primary school), maternal height (BMI), residential area (living in rural area) and socioeconomic status (being poor) were the main risk factors for stunting, underweight and wasting in Ethiopia. These findings are similar with the findings of a study conducted in Kenya that reported child age, child sex, maternal education and maternal height (BMI) as the main determinants of undernutrition(39).

The data presented here confirm that child undernutrition remains the most important public health problem in Ethiopia. There is nevertheless evidence that children throughout the world can attain their full growth potential if they are nurtured in healthy environments and their caregivers strictly stick to the recommended health, nutrition and care practices (40). Growth faltering often begins in utero and continues for the first two years of life (41). The main window of opportunity to prevent undernutrition is thus from pre-pregnancy to around 24 months of child age. Malnutrition in early life of a child will hinder the ability to bear healthy newborns and their capability to feed and care for them. Thus, these will distort the growth and development of the next generation (42).

Therefore, marked reductions in child undernutrition can be achieved through improving maternal nutrition, early initiation and exclusive breast feeding, and timely provision of good quality complementary feeding for infants and young children. Moreover, strengthing existing micronutrient interventions and community-based management of severe acute malnutrition programs (43).

The study limitations of this review include the great heterogeneity in the samples of the

DOI: http://dx.doi.org/10.4314/ejhs.v27i2.10 
retrieved studies regarding sample size and place of study. In order to explore the source of heterogeneity, a subgroup analyses was performed, and sensitivity analyses were done for high quality studies. However, most of the articles did not reported the outcomes for boys and girls separately, subgroup analysis based on gender were not performed. Regardless of the limitations, the present findings revealed a useful basis for monitoring trends and risk factors for undernutrition in Ethiopia. This study revealed that the prevalences of stunting, underweight and wasting are extremely high in Ethiopia. Thus, the implementation of policies to reverse child undernutrition should get maximum emphasis. The most important implication of this review for research is that there is a need for frequent research to realize and clarify the trend and risk factors for undernutrition among children in Ethiopia. Moreover, it would be of great concern to determine the extent to which the economic crisis had an effect on undernutrition in Ethiopia.

\section{ACKNOWLEDGEMENTS}

We would like to express our gratitude and appreciation to all staffs of Tehran University of Medical Sciences, School of nutritional Sciences and Dietetics who assisted in this review.

\section{REFERENCES}

1. Initiative M. Investing in the Future: A United Call to Action on Vitamin and Mineral Deficiencies: Global Report, 2009: Micronutrient Initiative; 2009.

2. Brauer J. Analog forestry as an opportunity for a healthier nutrition of the inhibitants of a rural village in Costa Rica: University of Cologne; 2014.

3. UNICEF. Progress for children: a report card on nutrition: UNICEF; 2006.

4. Shrimpton R, Victora CG, de Onis M, Lima RC, Blössner M, Clugston G. Worldwide timing of growth faltering: implications for nutritional interventions. Pediatrics. 2001;107(5):e75-e.

5. Ethiopia GotFDRo. National Nutrition Programme June 2013-June 2015. Government of the Federal Democratic Republic of Ethiopia. 2013.
6. CSA. Ethiopia Mini Demographic and Health Survey. Central Statistical Agency [Ethiopia]2014.

7. Moher D, Liberati A, Tetzlaff J, Altman DG. Preferred reporting items for systematic reviews and meta-analyses: the PRISMA statement. Annals of internal medicine. 2009;151(4):264-9.

8. Lien N, Henriksen HB, Nymoen LL, Wind M, Klepp K-I. Availability of data assessing the prevalence and trends of overweight and obesity among European adolescents. Public health nutrition. 2010;13(10A):1680-7.

9. Wells G, Shea B, O'connell D, Peterson J, Welch V, Losos M, et al. The NewcastleOttawa Scale (NOS) for assessing the quality of nonrandomised studies in meta-analyses. Ottawa Hospital Research Institute. 2000. Available:www.ohri.ca/programs/clinical_epi demiology/oxford.asp Accessed 25 June 2016.

10. Hardy RJ, Thompson SG. Detecting and describing heterogeneity in meta-analysis. Statistics in medicine. 1998;17(8):841-56.

11. Higgins JP, Thompson SG. Quantifying heterogeneity in a meta-analysis. Statistics in medicine. 2002;21(11):1539-58.

12. Egger M, Smith GD, Altman D. Systematic reviews in health care: meta-analysis in context: John Wiley \& Sons; 2008.

13. DerSimonian R, Laird N. Meta-analysis in clinical trials. Controlled clinical trials. 1986;7(3):177-88.

14. Haidich A. Meta-analysis in medical research. Hippokratia. 2010;14(Suppl 1):29.

15. Alemayehu M, Tinsae F, Haileslassie K, Seid O, Gebregziabher G, Yebyo H. Undernutrition status and associated factors in under-5 children, in Tigray, Northern Ethiopia. Nutrition. 2015;31(7-8):964-70.

16. Asfaw M, Wondaferash M, Taha M, Dube L. Prevalence of undernutrition and associated factors among children aged between six to fifty nine months in Bule Hora district, South Ethiopia. BMC Public Health. 2015;15(1).

17. Asres G, Eidelman AI. Nutritional assessment of ethiopian beta-israel children: A crosssectional survey. Breastfeeding Medicine. 2011;6(4):171-6. 
18. Bogale A, Stoecker BJ, Kennedy T, HubbsTait L, Thomas D, Abebe Y, et al. Nutritional status and cognitive performance of motherchild pairs in Sidama, Southern Ethiopia. Maternal and Child Nutrition. 2013;9(2):27484.

19. CSA. Ethiopia 2000: results from the Demographic and Health Survey. Studies in family planning. 2002;33(4):352-6.

20. CSA. Ethiopia 2005: Results from the demographic and health survey. Studies in Family Planning. 2007;38(2):135-40.

21. Deribew A, Alemseged F, Tessema F, Sena L, Birhanu Z, Zeynudin A, et al. Malaria and under-nutrition: A community based study among under-five children at risk of malaria, South-West Ethiopia. PLoS ONE. 2010;5(5).

22. Fekadu Y, Mesfin A, Haile D, Stoecker BJ. Factors associated with nutritional status of infants and young children in Somali Region, Ethiopia: A cross- sectional study Global health. BMC Public Health. 2015;15(1).

23. Fentaw R, Bogale A, Abebaw D. Prevalence of child malnutrition in agro-pastoral households in Afar regional State of ethiopia. Nutrition Research and Practice. 2013;7(2):122-31.

24. Gurmu E, Etana D. Household structure and children's nutritional status in Ethiopia. Genus. 2013;69(2):113-30.

25. Haidar J, Abate G, Kogi-Makau W, Sorensen P. Risk factors for child under-nutrition with a human rights edge in rural villages of North Wollo, Ethiopia. East Afr Med J. 2005;82(12):625-30.

26. Harpham T, Huttly S, De Silva MJ, Abramsky T. Maternal mental health and child nutritional status in four developing countries. Journal of Epidemiology and Community Health. 2005;59(12):1060-4.

27. Lindtjørn B, Alemu T. Intra-household correlations of nutritional status in rural Ethiopia. International Journal of Epidemiology. 1997;26(1):160-5.

28. Motbainor A, Worku A, Kumie A. Stunting is associated with food diversity while wasting with food insecurity among underfive children in East and West Gojjam Zones of Amhara Region, Ethiopia. PLoS ONE. 2015;10(8).
29. Mulugeta A, Hagos F, Kruseman G, Linderhof V, Stoecker B, Abraha Z, et al. Child malnutrition in Tigray, northern Ethiopia. East African medical journal. 2010;87(6):248-54.

30. Nguyen PH, Saha KK, Ali D, Menon P, Manohar S, Mai LT, et al. Maternal mental health is associated with child undernutrition and illness in Bangladesh, Vietnam and Ethiopia. Public Health Nutrition. 2014;17(6):1318-27.

31. Salama P, Assefa F, Talley L, Spiegel P, Van Der Veen A, Gotway CA. Malnutrition, measles, mortality, and the humanitarian response during a famine in Ethiopia. Journal of the American Medical Association. 2001;286(5):563-71.

32. Umeta M, West CE, Verhoef H, Haidar J, Hautvast JGAJ. Factors associated with stunting in infants aged 5-11 months in the Dodota-Sire District, Rural Ethiopia. Journal of Nutrition. 2003;133(4):1064-9.

33. UNICEF-WHO-WB U-W-TWBJCME. Levels and Trends in Child Malnutrition. UNICEF, WHO, World Bank Group joint malnutrition estimates 2015 edition. Avaialable;

www.unicef.org/media/files/JME_2015_editi on_Sept_2015.Accessed 15 July 2016

34. Abdi A, Vrieling A, Yengoh GT, Anyamba A, Seaquist J, Ummenhofer CC, et al. The El Niño-La Niña cycle and recent trends in supply and demand of net primary productivity in African drylands. Climatic Change. 2016;138(1-2):111-25.

35. Simane B, Beyene H, Deressa W, Kumie A, Berhane K, Samet J. Review of Climate Change and Health in Ethiopia: Status and Gap Analysis. The Ethiopian Journal of Health Development (EJHD). 2016.

36. Hagos S, Lunde T, Mariam DH, Woldehanna T, Lindtjørn B. Climate change, crop production and child under nutrition in Ethiopia; a longitudinal panel study. $B M C$ public health. 2014;14(1):1.

37. FMoH. HSDP IV. Health Sector Strategic Plan 2010/11-2014/15. Federal Ministry of Health, Addis Ababa.2010.

38. Mekuria EF. Spatial and temporal analysis of recent drought using Vegetation Temperature

DOI: http://dx.doi.org/10.4314/ejhs.v27i2.10 
Condition Index: case of Somali regional state of Ethiopia. RUN NOVA Information Management School. 2012.

39. Masibo PK, Makoka D. Trends and determinants of undernutrition among young Kenyan children: Kenya Demographic and Health Survey; 1993, 1998, 2003 and 20082009. Public health nutrition. 2012;15(09):1715-27.

40. Onis M. Assessment of differences in linear growth among populations in the WHO Multicentre Growth Reference Study. Acta Paediatrica. 2006;95(S450):56-65.

41. Victora CG, de Onis M, Hallal PC, Blössner M, Shrimpton R. Worldwide timing of growth faltering: revisiting implications for interventions. Pediatrics. 2010:peds. 20091519.
42. Godfrey K, Barker D, Robinson S, Osmond C. Maternal birthweight and diet in pregnancy in relation to the infant's thinness at birth. BJOG: An International Journal of Obstetrics \& Gynaecology. 1997;104(6):663-7.

43. Communication UDo. Tracking progress on child and maternal nutrition: a survival and development priority: UNICEF; 2009.

Avaialable:

www.unicef.org/.../Tracking_Progress_on_Ch ild_and_Maternal_Nutrition_EN. Accessed 10 June 2016. 